\title{
Modern improvement techniques of direct torque control for induction motor drives - a review
}

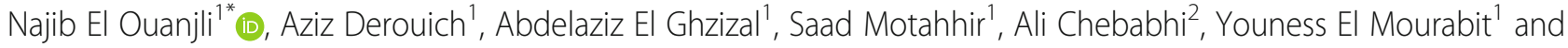 \\ Mohammed Taoussi ${ }^{3}$
}

\begin{abstract}
Conventional direct torque control (DTC) is one of the excellent control strategies available to control the torque of the induction machine (IM). However, the low switching frequency of the DTC causes high ripples in the flux and torque that leads to an acoustic noise which degrades the control performances, especially at low speeds. Many direct torque control techniques were appeared to remedy these problems by focusing specifically on the torque and flux. In this paper, a state of the art review of various modern techniques for improving the performance of DTC control is presented. The objective is to make a critical analysis of these methods in terms of ripples reduction, tracking speed, switching loss, algorithm complexity and parameter sensitivity. Further, it is envisaged that the information presented in this review paper will be a valuable gathering of information for academic and industrial researchers.
\end{abstract}

Keywords: Induction machine, Direct torque Control (DTC), Fuzzy logic (FL), Neural network (NN), Sliding mode (SG), Genetic algorithm (GA)

\section{Introduction}

In industry, more than half of the total electrical energy produced is consumed by electric motors [1]. Among several types of electric motors, three-phase induction machines (IMs) occupy a prominent place. Indeed, at least $80 \%$ of industrial control systems use induction motors [2], which have gradually taken the place of DC machines because of their good performance: reliability, simple construction, low cost and simple maintenance $[3,4]$. However, these numerous advantages are not without inconvenience, the dynamic behavior of the machine is often very complex $[5,6]$, since its modeling results in a system of nonlinear equations, strongly coupled and multivariable. In addition, some of its state variables, such as flux, are not measurable [7]. These constraints require more advanced control algorithms to control the torque and flux of these machines in real time [8]. For several

\footnotetext{
* Correspondence: najib.elouanjli@usmba.ac.ma

${ }^{1}$ Laboratory of Production Engineering, Energy and Sustainable

Development, Higher School of Technology, Sidi Mohamed Ben Abdellah

University, Fez, Morocco

Full list of author information is available at the end of the article
}

years, academic and industrial research has been carried out to remedy the control problem of the IM and to develop robust and efficient controls [9].

In this context, scalar control is the first technique that has been developed to control electrical machines, this control strategy consists of keeping the $V / f$ constant to keep the flux in the machine constant $[10,11]$. It is characterized by its simplicity of implementation, its simple structure, which is based on the stator flux control [12]. However, on a start-up or for change the rotation direction of the machine, the flux oscillates strongly with large amplitudes and its modulus is variable during the transient states $[13,14]$. These oscillations will impact the quality of the torque and the speed, thus degrading the performances in transient state of the machine. This type of control is therefore used only for applications where the speed variation is not great, such as in pumping or ventilation $[15,16]$.

Subsequently, the Field Oriented Control (FOC) method was developed to control transient torque [5]. This control provides a behavior of the IM similar to that of the DC machine with a decoupling between the 
torque and the flux of the machine [17-19], this decoupling provides a very fast torque response, a large speed control range and high efficiency for a wide load range. However, this control also has a high sensitivity to the parametric variations of the machine especially that of the resistors whose value changes substantially with temperature [20-22]. Any difference between the parameters used by the FOC algorithm and the actual parameters of the machine is translated by errors in the output values of the flux and the torque, which leads to increased losses in the machine and reduced performance of the system to be controlled [23].

In the middle of 1980s, Direct Torque Control (DTC) was introduced to compete with conventional controls. This technique was introduced by TAKAHASHI [24] and DEPENBROCK [25]. It has remarkable dynamic performance as well as good robustness with respect to the variations of the parameters of the machine. Its principle is based on a direct determination of the control pulses applied to the switches of the voltage inverter [26-28]. However, two major drawbacks arise: (i) the switching frequency is highly variable and (ii) the undulations amplitude of the torque and the stator flux remain poorly controlled throughout the speed range of the envisaged operation [29-31]. It should be mentioned that the ripples in the torque generate additional noise and vibrations and therefore cause disturbances in the rotating shaft [32].

Currently, a lot of research has tried to solve these problems. The Artificial Intelligence (AI) control is a vocabulary that has emerged in recent years and occupies a large place in modern research fields. Fuzzy logic, neural networks and genetic algorithms are the major families that constitute AI. In [29, 33], the authors propose AI techniques to improve the dynamic performance of the DTC control, these control methods can provide performance optimization under different operating conditions aiming ripples reduction of the torque and flux, THD reduction, efficiency improvement, energy savings and etc.

From published literature, different works considering DTC schemes for induction motor drives, but these schemes are not reviewed critically. Our contribution of this work is to review different modern techniques for improving the performance of direct torque control; the aim is to give an idea to researchers who are interested in the current state of the art of DTC strategy and work on new lines of research.

This review paper is organized as follows: Section 2 presents the three-phase mathematical model of the IM and its transformation in the two-phase system. A representation in the form of a state is developed from the physical laws that govern its operation by supplying the machine with voltage. Section 3 discusses the classical DTC technique based on the switch table and hysteresis controllers and the main problems encountered during this control strategy. Section 4 discusses some techniques for improving conventional DTC, briefly recalling some typical techniques and dealing with modern techniques based on artificial intelligence. Section 5 presents a comparative study between the improvement methods presented, a table summarizing the comparison is presented at the end of this article which aims to help in the choice of the appropriate command for the specific application given, and Section 6 summarizes the conclusions of the paper.

\section{Dynamic model of induction machine}

The most appropriate model to study the dynamic behavior and control algorithms design of the three-phase IM is the two-phase model expressed by the reference $(\alpha, \beta)[34,35]$. This model reduces the complexity of the three-phase representation $(\mathrm{a}, \mathrm{b}, \mathrm{c})$ of the machine.

The electromagnetic equations of the induction machine in the reference frame $(\alpha, \beta)$ are given by $[36,37]$ :

$$
\begin{aligned}
\frac{d}{d t}\left[\begin{array}{l}
i_{s \alpha} \\
i_{s \beta} \\
\psi_{s \alpha} \\
\psi_{s \beta}
\end{array}\right] & =\left[\begin{array}{cccc}
-\frac{1}{\sigma}\left(\frac{1}{\tau_{s}}+\frac{1}{\tau_{r}}\right) & -\frac{1}{\sigma}\left(\frac{1}{\tau_{s}}+\frac{1}{\tau_{r}}\right) & \frac{1}{\sigma L_{s} \tau_{r}} & \frac{\omega_{r}}{\sigma L_{s}} \\
\omega_{r} & -\frac{1}{\sigma L_{s}} & \frac{1}{\sigma L_{s} \tau_{r}} \\
-R_{s} & 0 & 0 & 0 \\
0 & -R_{s} & 0 & 0
\end{array}\right] \cdot\left[\begin{array}{l}
i_{s \alpha} \\
i_{s \beta} \\
\psi_{s \alpha} \\
\psi_{s \beta}
\end{array}\right] \\
& +\left[\begin{array}{cc}
\frac{1}{\sigma L_{s}} & 0 \\
0 & \frac{1}{\sigma L_{s}} \\
1 & 0 \\
0 & 1
\end{array}\right] \cdot\left[\begin{array}{l}
V_{s \alpha} \\
V_{s \beta}
\end{array}\right]
\end{aligned}
$$

With $\sigma, \tau_{s}$ and $\tau_{r}$ are positive constants defined as:

$$
\sigma=1-\frac{M^{2}}{L_{s} L_{r}} \quad \tau_{s}=\frac{R_{s}}{L_{s}} \quad \tau_{r}=\frac{R_{r}}{L_{r}}
$$

The equations of electromagnetic torque and the movement are given by the following expressions:

$$
\begin{aligned}
& T_{e m}=p\left(\psi_{s \alpha} i_{s \alpha}-\psi_{s \beta} i_{s \beta}\right) \\
& J . \frac{d \Omega}{d t}+f . \Omega=T_{e m}-T_{r}
\end{aligned}
$$

The passage of a three-phase reference $(\mathrm{a}, \mathrm{b}, \mathrm{c})$ towards a two-phase reference $(\alpha, \beta)$ can be achieved by the transformation called Concordia [38], this transformation is given by:

$$
\left[\begin{array}{l}
X_{\alpha} \\
X_{\beta}
\end{array}\right]=\sqrt{\frac{2}{3}} \cdot\left[\begin{array}{ccc}
1 & -\frac{1}{2} & -\frac{1}{2} \\
0 & \frac{\sqrt{3}}{2} & -\frac{\sqrt{3}}{2}
\end{array}\right] \cdot\left[\begin{array}{l}
X_{a} \\
X_{b} \\
X_{c}
\end{array}\right]
$$

With: X can be a current, voltage or the flux of the machine. 


\section{Direct torque control}

The direct torque control (DTC) for induction machines was proposed in the middle of 1980 s by Takahashi [24] and Depenbrock [25]. Comparing to the vector control, it is less sensitive to parametric variations of the machine $[18,39]$, its control algorithm is simple because of the absence of pulse width modulation (PWM), of Current Controllers and Park Transformations [40, 41]. It does not use PI regulation loops, which should improve its dynamic skills a priori and eliminate the problems related to the saturation of PI regulators. DTC control ensures high efficiency operation and provides accurate and fast torque dynamics. The principle of DTC is based on the direct application of a control sequence to the switches of the voltage inverter (switching states) placed upstream of the machine [42-45]. The choice of this sequence is made by the use of a switching table and two hysteresis regulators whose role is to control and regulate the electromagnetic torque and the flux of the machine in a decoupled manner. Fig. 1 shows a simple structure of the DTC control. The electromagnetic torque is controlled using a three level hysteresis comparator. While the stator flux is controlled using a two level hysteresis comparator. The outputs of these comparators, as well as the flux vector information, are used to determine the switching table.

In DTC, the accuracy of electromagnetic torque and stator flux estimation is very important to ensure satisfactory performance $[34,46]$. So, several parameters must be determined, the stator current is measured while the stator voltage depends on the switching state $\left(\mathrm{S}_{\mathrm{a}}, \mathrm{S}_{\mathrm{b}}\right.$ and $\left.\mathrm{S}_{\mathrm{c}}\right)$ produced by the switching table and the DC link voltage $U_{\mathrm{dc}}$ [47]. These parameters are transformed into coordinates $(\alpha, \beta)$, by the Concordia transformation Eq. (4), which are suitably adapted to the DTC algorithm.

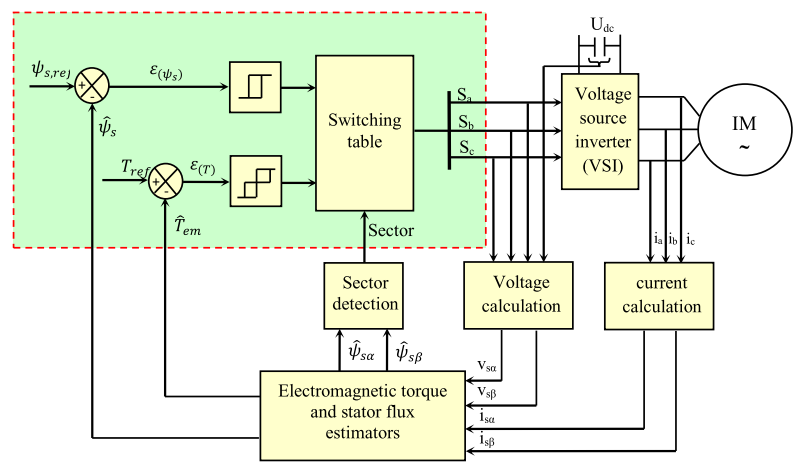

Fig. 1 Synoptic schema of DTC control of the induction machine
The stator flux $\psi_{\mathrm{s}}$ and the electromagnetic torque Tem are estimated from the following equations:

$$
\begin{aligned}
& \hat{\psi}_{s}=\sqrt{\hat{\psi}_{s \alpha}^{2}+\hat{\psi}_{s \beta}^{2}} \\
& T_{e m}=p \cdot\left(\hat{\psi}_{s \alpha} \cdot i_{s \beta}-\hat{\psi}_{s \beta} \cdot i_{s \alpha}\right)
\end{aligned}
$$

The angle $\theta_{\mathrm{s}}$ is calculated from:

$$
\theta_{s}=\operatorname{arctg}\left(\frac{\hat{\psi}_{s \beta}}{\hat{\psi}_{s \alpha}}\right)
$$

With the stator flux components in the reference $(\alpha$, $\beta)$ are:

$$
\left\{\begin{array}{l}
\hat{\psi}_{s \alpha}=\int_{0}^{t}\left(v_{s \alpha}-R_{s} \cdot i_{s \alpha}\right) \cdot d t \\
\hat{\psi}_{s \beta}=\int_{0}^{t}\left(v_{s \beta}-R_{s} \cdot i_{s \beta}\right) \cdot d t
\end{array}\right.
$$

Then, the estimated values of the electromagnetic torque Test and the stator flux $\psi_{\text {est }}$ are compared respectively to their reference values $\mathrm{T}_{\mathrm{em}} *$ and $\psi_{\mathrm{s}^{*}}$, the results of the comparison form the inputs of the hysteresis comparators [48]. The selection of the appropriate voltage vector is based on the control table [10] (Table 1). The inputs of this table are the flux sector number and the outputs of the two hysteresis comparators.

Despite its simplicity, robustness and speed, the DTC control has major disadvantages. The use of hysteresis controllers causes high ripples in the flux and electromagnetic torque that generate mechanical vibrations and undesirable acoustic noise, and therefore, a deterioration of the machine performances [34, 49], thus a variable switching frequency and current distortions that can degrade the quality of the output power $[50,51]$. The negligence of stator resistance causes problems at low speed. In addition, the practical implementation of nonlinear elements of the hysteresis type requires a rather low sampling period, and therefore a high calculation frequency leading to constraining architectures [52].

In recent years, many direct control strategies have emerged to overcome the problems of conventional DTC. These strategies are based on the same principle of instantaneous torque and stator flux regulation and the direct determination of the inverter control signals from a switching table. Generally, these control methods can be divided into two categories: typical and modern techniques. These include: Vector Spatial Modulation (SVM) [53], sliding mode based DTC, model predictive DTC and artificial intelligence (fuzzy logic, neural network and genetic algorithm) [54, 55]. Fig. 2 illustrates a 
Table 1 Switching table

\begin{tabular}{|c|c|c|c|c|c|c|c|}
\hline \multicolumn{2}{|c|}{ Sector } & 1 & 2 & 3 & 4 & 5 & 6 \\
\hline $\mathrm{H} s$ & $\mathrm{H}_{\mathrm{Tem}}$ & \multicolumn{6}{|c|}{ Voltage vector } \\
\hline \multirow[t]{3}{*}{1} & 1 & $v_{2}$ & $v_{3}$ & $v_{4}$ & $v_{5}$ & $v_{6}$ & $v_{1}$ \\
\hline & 0 & $v_{7}$ & $v_{0}$ & $v_{7}$ & $v_{0}$ & $v_{7}$ & $v_{0}$ \\
\hline & -1 & $v_{6}$ & $v_{1}$ & $v_{2}$ & $v_{3}$ & $v_{4}$ & $v_{5}$ \\
\hline \multirow[t]{3}{*}{0} & 1 & $v_{3}$ & $v_{4}$ & $v_{5}$ & $v_{6}$ & $v_{1}$ & $v_{2}$ \\
\hline & 0 & $v_{0}$ & $v_{7}$ & $v_{0}$ & $v_{7}$ & $v_{0}$ & $v_{7}$ \\
\hline & -1 & $v_{5}$ & $v_{6}$ & $v_{1}$ & $v_{2}$ & $v_{3}$ & $v_{4}$ \\
\hline
\end{tabular}

classification of the methods used to improve the DTC control of an induction machine.

\section{Improvement techniques of direct torque control}

\subsection{Typical improvement techniques of direct torque control}

Several authors have used the Space Vector Modulation (SVM) technique in controlling the voltage inverter to improve DTC [56-58]. The principle of this technique consists in imposing the appropriate vector of tension via a vector modulation of space, in order to proceed to a predictive regulation of the torque and the flux. The control algorithm for this method is more complex, but flux and torque oscillations are reduced and the average switching frequency of the inverter became constant [59]. Like any predictive method, the DTC-SVM has some static torque error for control without a speed loop during a practical implementation. Indeed, this error is due to the computation time necessary for the prediction of the control voltage.

The authors of [56] have developed a method that makes it possible to obtain a constant switching frequency. This strategy is characterized by the elimination of the Takahashi selection table and the hysteresis comparators. In this context, the PWM technique is used to generate the output vector of the control. The objective of this strategy is to realize a direct control of the stator flux vector in a frame $(\alpha, \beta)$ linked to the stator. The projection components of the desired stator voltage vector on the two adjacent voltage vectors of the frame $(\alpha, \beta)$ allow the calculation of the desired switching times.

In $[60,61]$, a method of direct torque control of the IM based on pulse width modulation (PWM) has been proposed to have a constant switching frequency. The proposed control technique is developed in discrete time to allow the implementation on microcontrollers or DSP boards. The authors use simulations and experimental tests to validate the proposed method. In [62, 63], the authors showed that the conventional DTC has a low number of voltage vectors applied to the machine, which causes undesirable oscillations of the torque, flux and current. This work shows that improved performance can be achieved by using a new DTC algorithm, based on the application of SVM for fixed time intervals. In this way, a Discrete Space Vector Modulation (DSVM) using a five-levels torque comparator to produce a higher voltage vector number. Numerical simulations and experimental tests show improved torque and flux response with fixed switching frequency.

Some authors adapted the DTC to the control of machines powered by inverters of multilevel voltage types [64], indeed, the higher number of control vectors promotes a minimization of the resulting ripple in steady state. In $[64,65]$ a three-level inverter is applied to the DTC, for the reduction of the torque ripples, but the disadvantage of this arrangement is the

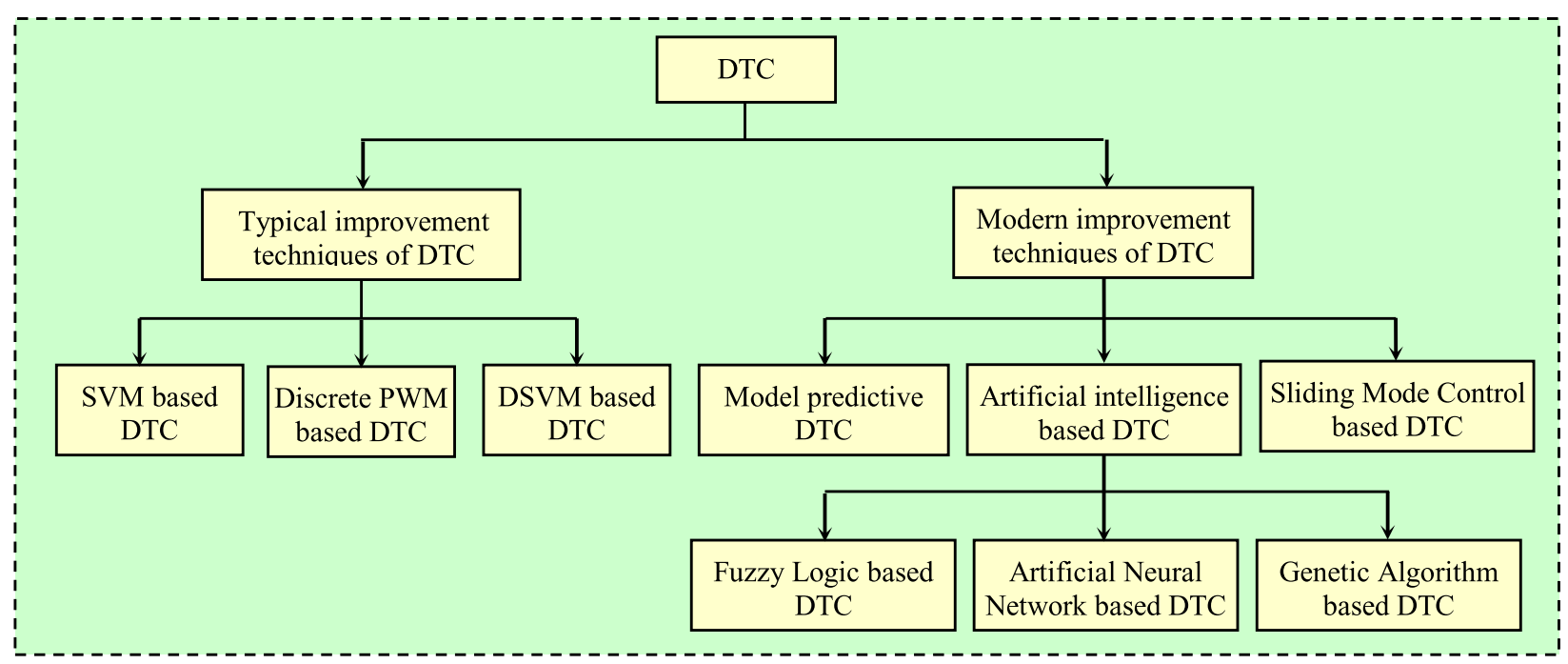

Fig. 2 Classification of improvement techniques of direct torque control 
high cost. They are very useful, especially in high power controls.

\subsection{Modern improvement techniques of direct torque control}

\subsubsection{Sliding mode based DTC}

Sliding Mode Control (SMC) is a class of the Variable Structure Control (VSC) introduced by Utkin [66], it is mostly known for its robustness towards internal uncertainties (variations of machine parameters), external uncertainties (perturbation due to the load), and phenomena that have been omitted in the modeling [67, 68]. The main characteristic of SMC is manifested in the modified control law in a discontinuous manner [69]. However, it has certain drawbacks: the appearance of the chattering phenomenon caused by the discontinuous part of the control which can have a detrimental effect on the machines [70], at every moment, the system is subject to high control in order to ensure its convergence to the desired and this is not desirable.

The SMC technique was studied to improve DTC for IMs $[68,71,72]$. These techniques improve the steady-state performance and keep advantages of transient state $[73]$. In $[68,73]$ the authors begin to use a discrete time sliding mode control strategy so that the torque and flux are robust against the variation of the machine parameters. The controllers supply the reference voltages $\left(\mathrm{V}_{\mathrm{sa}}, \mathrm{V}_{\mathrm{sb}}\right)$ for application to the $\mathrm{IM}$ and no controller current is used. However, unlike most sliding mode techniques, the reference voltage vector is calculated by a PWM vector system and a fixed switching frequency is used. Simulations and experimental results are presented to show the effectiveness of the proposed strategy.

Fig. 3 illustrates the general scheme of the direct torque control structure and the flux based on the sliding mode of an induction machine (DTC-SMC) controlled in speed. It is a cascade command for the control of the electromagnetic torque, the square norm of the flux and the speed. So there are sliding regimes control algorithms to implement in the control structure for adjusting the

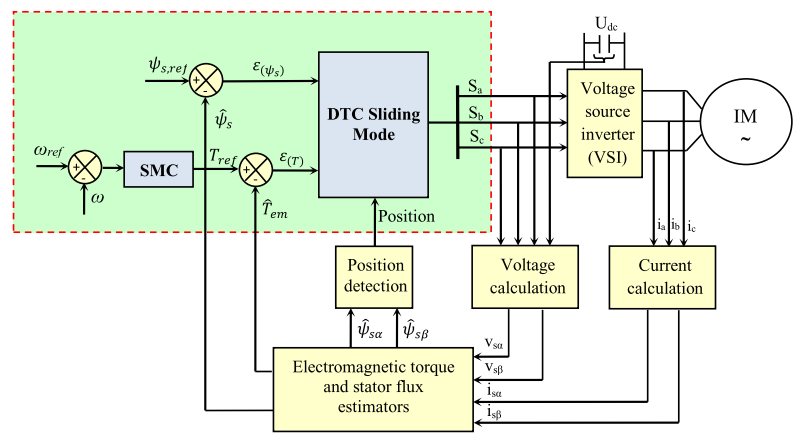

Fig. 3 Synoptic schema of DTC-SMC control of the induction machine torque, flux and speed. The "estimator" block consists of the flux and torque estimator which only uses the measurement of voltages and stator currents in the reference $(\alpha, \beta)$. This control scheme is fast and robust. However the controlled magnitude presents undesirable chattering.

Other works used the robust sliding mode observer [74] to make the flux estimation less sensitive to the measurement noise.

\subsubsection{Model predictive DTC}

Predictive control is an advanced control technique of the automatic. Its objective is to control complex industrial systems. The principle of this technique is based on the calculation of the future behavior of the system based on the dynamic model of the process inside the real-time controller, in order to be able to use this information to calculate the optimal values of the adjustment parameters [75]. The application of the model predictive control (MPC) in the field of digital controls has yielded good results in terms of speed and accuracy [76].

Recently, the predictive control strategy for DTC has received considerable attention, particularly because of its ability to minimize the switching frequency of the voltage inverter that supplies the machine and to reduce torque and flux ripples. In DTC-MPC, the traditional DTC switching table is replaced by an online optimization algorithm [77-79]. The principle of vector selection in predictive control is based on the evaluation of a defined cost function $[80,81]$. The predictive model with stator flux, torque and angular velocity is used to predict the future behavior of the controlled variables. The simplified diagram of DTC-MPC is illustrated in Fig. 4.

The execution of the predictive algorithm can be performed in three main steps:

- The estimation of non-measurable variables.

- The prediction of the future behavior of the system.

- The optimization of the control outputs, according to a cost function already defined before.

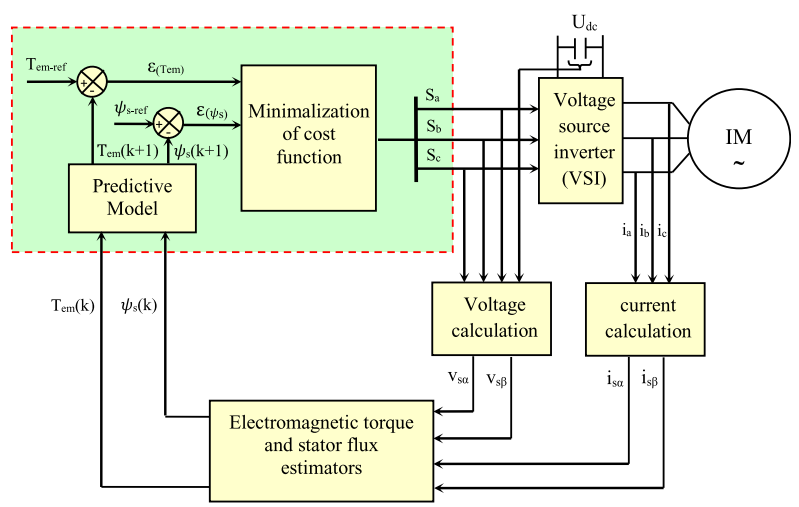

Fig. 4 Block diagram of the DTC-MPC 
These steps are repeated at each sampling time step, taking into account the new measurements. Closed-loop control is obtained by feedback from measurements used to predict and decide on measures taken to reduce the value of the cost function F. Fig. 5 shows the flowchart of the DTC-MPC.

Predictive control has many advantages, the MPC concept is very simple and intuitive, easy to achieve, the constraints and nonlinearities of the systems to be controlled can be included in the control and the case of multi-variable systems can be taken into consideration [34]. However, this type of control requires a lot of online calculation compared to conventional DTC.

In $[82,83]$, a predictive control strategy based on the optimization of a cost function defined on a horizon has been presented, to guarantee the rejection of disturbances and improve robustness to parameter variations and make

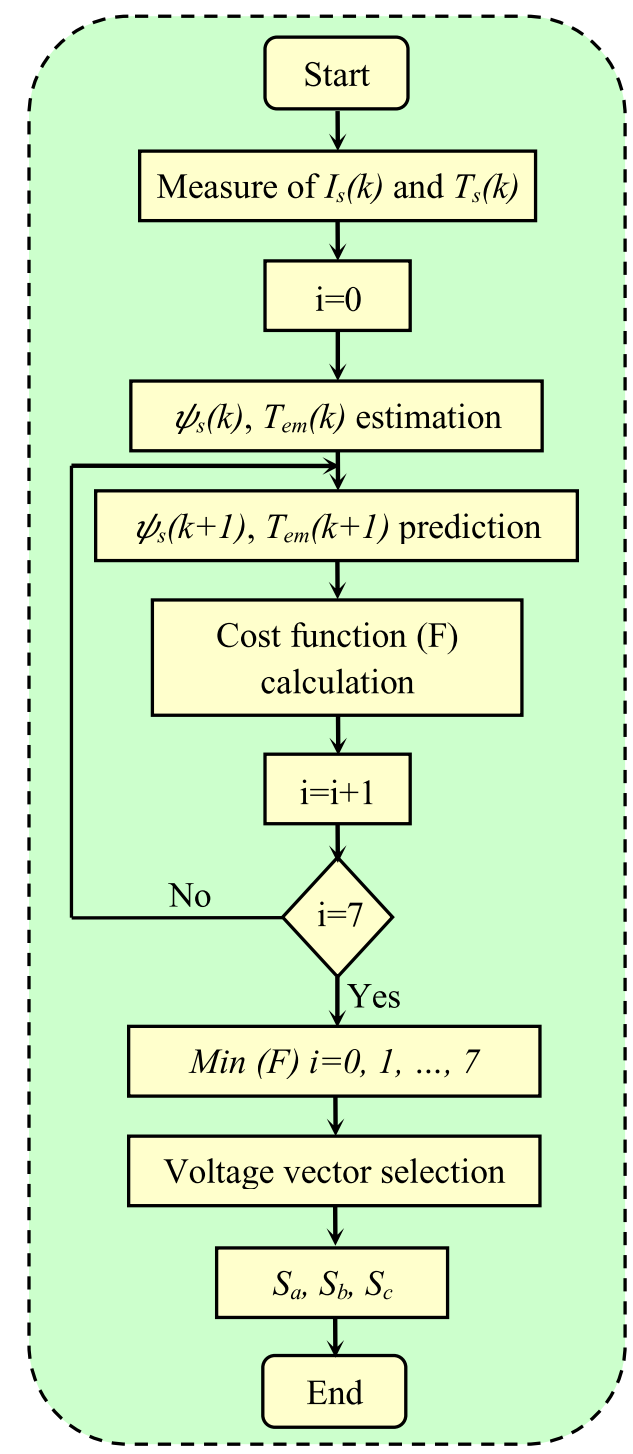

Fig. 5 Flowchart of the DTC-MPC the system more efficient. Also, in [45, 77-81, 84] the authors propose a technique to improve the dynamic performance of the DTC using predictive control, they have been shown that DTC-MPC provides better performance in terms of dynamics judged fast, reduction of torque and flux ripples and improvement of current shape.

\subsubsection{Artificial intelligence based direct torque control}

Recently, another category of control based on artificial intelligence is presented in the literature. These methods improve the dynamic performance of the DTC control, either by adapting the hysteresis band $[85,86]$, or by replacing the Takahashi switching table as well as the hysteresis by intelligent regulators [87-92]. Artificial intelligence such as fuzzy logic, the neural network and the genetic algorithm knew a big success not only in modeling but also in the control of electrical systems, in particular the control of IM. This success is due to the fact that artificial intelligence can easily get close to the control behavior of the human expert who works in often poorly defined environments. Therefore, in this section we will deal with the different artificial intelligence approaches introduced to the DTC control.

\subsubsection{Fuzzy logic based DTC}

Fuzzy logic, or more generally the treatment of uncertainties, is one of the classes of artificial intelligence [93], it is introduced to improve the performances of the different classical control strategies applied to variable speed drives.

In $[94,95]$, the authors propose the Fuzzy Direct Torque Control (FDTC) method to improve the dynamic performance of conventional DTC control. They develop a new selection table based on a fuzzy logic controller (FLC) to replace the switching table and the hysteresis comparators, in order to generate the vector voltage that drives the flux and torque to their references in an optimal way. Fig. 6 shows a general structure of the FDTC command applied to the induction machine.

The inputs of the fuzzy switching table are the stator flux error, the electromagnetic torque error and the stator flux vector position, while the outputs are the switching states of the inverter arms $\left(S_{a}, S_{b}, S_{c}\right)$ [96-98]. Each input and output is divided into a determined number of fuzzy sets so as to have better control using the minimum of rules.

The inference rules are written in such a way that the differences between the flux and torque set-points and their estimated values can be corrected. Six linguistic variables are used to represent the domain of the angle of the stator flux vector. Three linguistic variables $(\mathrm{N}$ : negative, $\mathrm{Z}$ : zero and $\mathrm{P}$ : positive) are used to fuzzify the speech universe of $\varepsilon_{\mathrm{Tem}}$. And two linguistic variables (N: negative and P: positive) are used to fuzzify the speech universe of $\varepsilon_{\psi}$. The discourse universe of each output is 


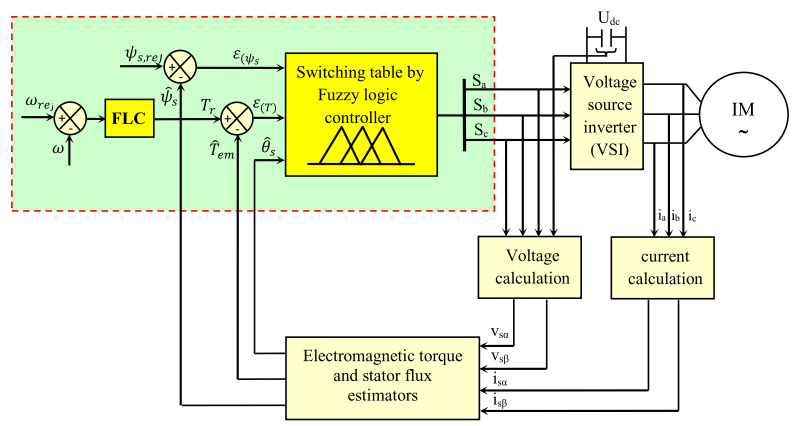

Fig. 6 Synoptic schema of DTC-Fuzzy control of the induction machine

divided into two fuzzy sets (zero and one). The membership functions adopted for making the fuzzy table and the inference rules are shown in Fig. 7.

In [87], the authors proposed a DTC strategy based on fuzzy logic. The objective of the work is to improve the performance of the DTC control while minimizing the torque at low speeds. They have integrated a fuzzy speed regulator which makes it possible to dynamically adjust the integration coefficient $k_{i}$ and the coefficient of proportionality $k_{p}$ as a function of the error and of the variations of the speed. In addition, the flux and torque hysteresis are replaced by a fuzzy controller to optimize the selection of the voltage vector. The experimental results show that the proposed fuzzy control system can provide a fast response and a high precision of the steady state speed, as well as the remarkable reduction of torque ripples even at low speeds.

Besides, fuzzy logic is used to control the limits of the electromagnetic torque hysteresis band [99], what entails a minimization of the torque undulations as well as an improvement of the dynamic performances. In the same context, Uddin Nasir et al. [86] proposed a fuzzy controller to adjust the hysteresis band in real time. This adjustment is based on the slopes of the variation of the estimated torque and the stator current, where the fuzzy controller selects the optimum bandwidth of the torque hysteresis. The simulation results from a model developed under Matlab/Simulink, as well as the experimental

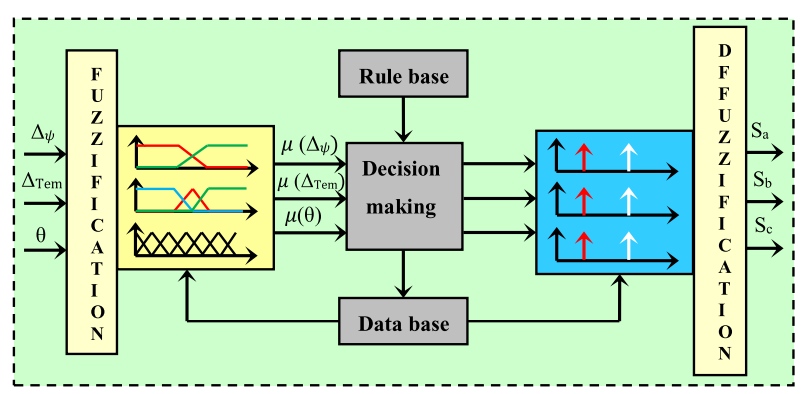

Fig. 7 Structure of the fuzzy switching table results realized with a DSP board prove the performances obtained by this fuzzy controller. A comparative study between the DTC based on the proposed fuzzy controller and the conventional DTC shows that the torque ripple of the proposed control was considerably reduced.

In [100], fuzzy logic strategy is used to study the effect of parametric variation on DTC performance through the use of control tables developed by fuzzy logic reasoning. The validity of the proposed method has been proven by the simulation results. Fuzzy logic can cope with parameter uncertainties. However, the main problems of this technique are the difficult tuning of fuzzy logic parameters and the complexity of implementation; because fuzzy controller uses many rules base do the extensive experiments.

\subsubsection{Neural network based DTC}

The Artificial Neural Network (ANN) is widely used in many fields of technology application and scientific research. This technique can be used in cases of difficult problems that cannot be described by precise mathematical approaches where they are very complicated to manipulate [101]. The fields of application of these neural networks are very broad: classification, image and speech processing, estimation, process identification $[102,103]$ and control of electrical systems [104, 105]. In [106], the authors integrated artificial neural networks into the control of an induction machine; they mentioned that in some cases, where the dynamics of the system change over time and/ or with operating conditions, the efficiency of the PI regulator deteriorates and the quality of the adjustment deteriorates. To overcome these problems and to ensure a good performance of the command, the authors have integrated artificial neural networks in the speed control. Several tests have been simulated to assess the contribution of ANN. The results obtained make it possible to affirm an improvement of the performances and robustness in the control of the IM.

Several studies have suggested the application of the ANN technique to select the states of the voltage inverter switches used to power the DTC-controlled IM [107112]. The idea is always to replace the conventional switching table that determine the inverter states by neural selector capable of managing control signals in the same way. Fig. 8 shows the block diagram of Direct Torque Neural Control (DTNC). The architecture includes a multilayer neural network allowing replacing both hysteresis comparators and the selection table. This neural network is composed of an input layer, two hidden layers and an output layer. The input layer is composed of three neurons, designated respectively by the torque error, the flux error and the angular position $(\theta)$ of the stator flux vector. The two hidden layers each consist of ten neurons. The output layer consists of three neurons that 


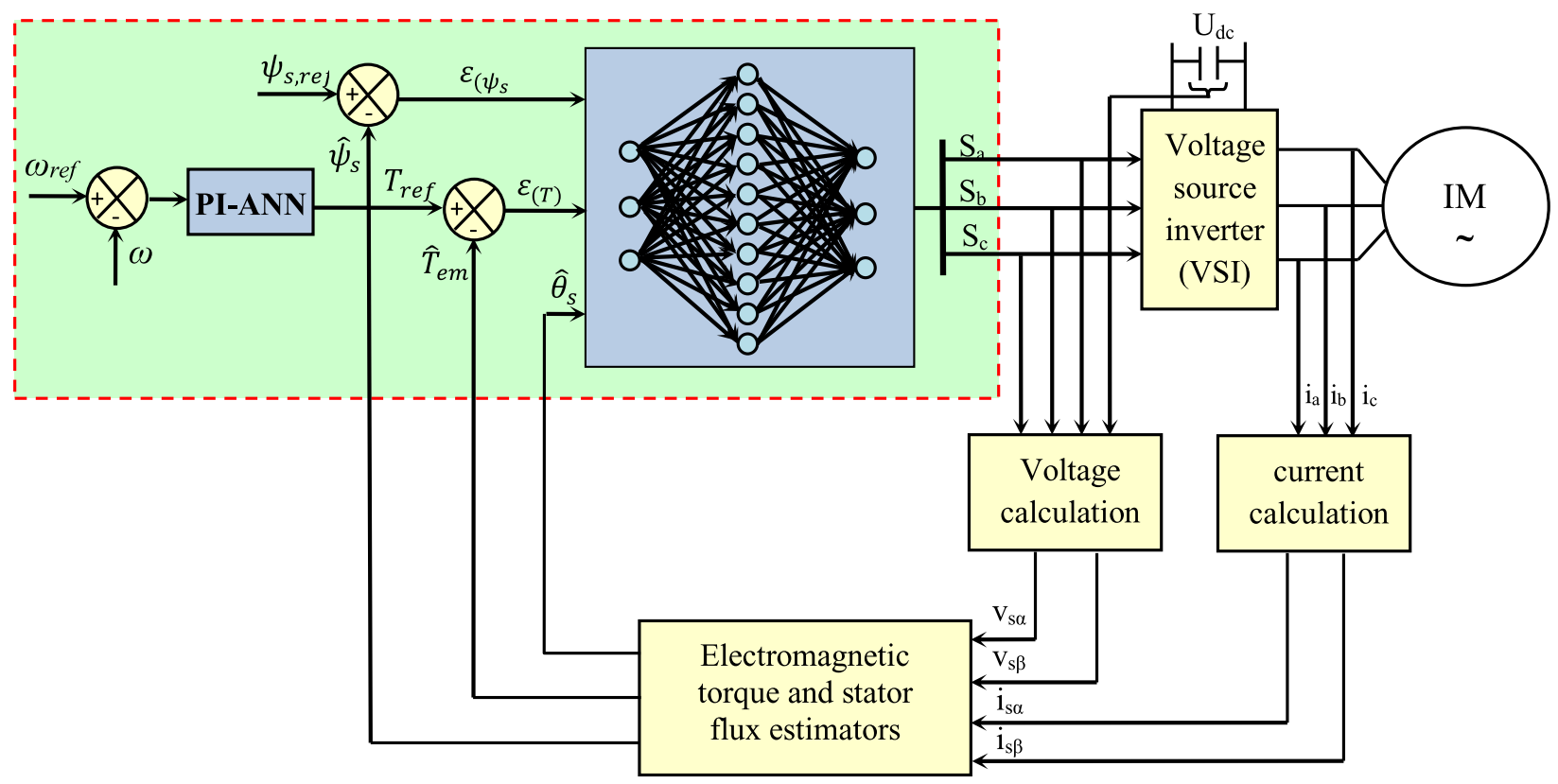

Fig. 8 Synoptic schema of DTC-ANN control of the induction machine

produce the reference voltage to be applied across the IM through the voltage inverter.

The application of neural networks to DTC ensures a good dynamic response of torque and flux with fixed switching frequency, which leads to a considerable reduction in torque ripples and the harmonic rate of the currents compared to other conventional techniques [107]. Moreover, it is very robust against the various uncertainties of the motor parameters [111]. However, this proposed technique has the disadvantage of the internal structure that is more complicated.

\subsubsection{Genetic algorithm based DTC}

Genetic Algorithms (GAs) represent a fairly rich and interesting family of stochastic optimization algorithms that are based on techniques derived from natural evolution and genetics [113]. The principle of these algorithms is to proceed by a stochastic search on a large space and through a population of pseudo-solutions [114]. The robustness against parametric variations is one of the main features of genetic algorithms; they allow to supply one or several good quality solutions to problems highly varied, by requesting a rather low investment (time and computing power) [115]. However, it has the disadvantage of parameters selection, because the choice of these parameters depends strongly on the studied problematic and the knowledge of the user regarding this problem.

Recently, the genetic algorithm is used to improve the dynamic performance of the DTC control; it is well adapted to optimize the gain values of the speed controller [116, 117].
In [116], the optimization technique (GA) has been applied to DTC, the authors use a PI regulator optimized by the genetic algorithm (PI-GA), This method showed better performance compared to conventional DTC in both transient and stable states, of which many advantages have been confirmed, related to torque and flux ripples, reduction of overshoot and response time.

In [118], the authors proposed a new DTC strategy, using a genetic algorithm to optimize the PI-fuzzy regulator. In this strategy, as a function of the speed error and its derivative with respect to time, the adjustment of the integral coefficient $k_{i}$ and proportional $k_{p}$ is realized in real time by an adaptive regulator PI-fuzzy of speed. The fuzzy parameters are refined by the genetic algorithm to improve the self-adaptation of the speed. In addition, the hysteresis regulators have been replaced by another fuzzy regulator to improve the choice of the voltage vector. Finally, the author presented a comparative study between Takahashi's conventional DTC, PI-fuzzy regulator and the proposed strategy. This study proved the significant decrease of the ripples at the torque level, flux, and current. As well as improving accuracy and speed tracking.

\section{Critical analysis}

Table 2 presents a critical analysis of the proposed methods for improving the performance of direct torque control in an induction machine. This analysis aims to highlight an idea for researchers who are interested in the DTC technique. The evaluation of these methods is 
Table 2 Critical analysis of the improvement techniques of direct torque control $[29,34,53-55,73,116,118-121]$

\begin{tabular}{llllllll}
\hline & Conventional & SVM based & SMC based & DTC-MPC & Fuzzy based & $\begin{array}{l}\text { ANN based } \\
\text { DTC }\end{array}$ & $\begin{array}{l}\text { GA based } \\
\text { DTC }\end{array}$ \\
\hline Torque dynamic response & Fast & Fast & Fast & Fast & Very fast & Very fast & Very fast \\
Torque and flux ripple & High & Low & Medium & Low & Very low & Very low & Medium \\
Current THD & More distortions & Less distortion & Less distortion & Less distortion & Less distortion & Less distortion & Less distortion \\
Switching frequency & Variable & Constant & Almost constant & Constant & Constant & Constant & Almost constant \\
Parameter sensitivity & Insensitive & Sensitive & Insensitive & Insensitive & Insensitive & Insensitive & Insensitive \\
Switching loss & High & Low & Medium & Low & Low & Low & Medium \\
Dynamic at low speed & Poor & Good & Good & Good & Very good & Very good & Very good \\
Algorithm complexity & Simple & Simple & Complex & Simple & More complex & More complex Complex \\
Computation time & Low & Medium & High & Medium & High & High & Medium \\
Precession & Low & Medium & Medium & Medium & High & High & Medium \\
Regulation & Hysteresis & Pl conventional & SMC controller & Hysteresis & FLC & ANN & GA-PI \\
\hline
\end{tabular}

carried out in terms torque and flux ripple, switching frequency, parameter sensitivity, steady-state and dynamic response and algorithm complexity. It should be mentioned that evaluation does not have a totally absolute meaning, because it is very difficult to find several works made under the same conditions and on the same type of machine, but the basic disadvantages and advantages must be the same for each control technique.

From this study, it can be said that conventional DTC presents the simplest structure among the other control strategies with a low switching frequency which is the major problem of DTC. In order to overcome these problems and obtain a sufficiently low torque ripple, the sampling frequency must necessarily be high. Artificial intelligence techniques and the predictive model of DTC can achieve lower torque ripple and switching frequency than that of the direct torque control under the same sampling frequency, but the complexity of AI methods is substantially elevated. Therefore, it can be employed for high precision control in high power applications. Moreover, SVM and SMC methods can be solutions to improve DTC, but they have limitations such as sensitivity and chattering phenomenon.

The preferred approach to solve the complexity problem is to simplify the control algorithm without increasing the calculation capacity of the microprocessor. On the other hand, it is possible to improve the performance of the DTC drive and to obtain a low-cost system, by developing a hybrid control strategy by combining two or more modern techniques.

\section{Conclusion}

In this paper, several modern improvement techniques of direct torque control for an induction motor are reviewed. The objective of this improvement is to minimize the ripples of the couple and the flux of the IM on the one hand and the decrease of the switching frequency of the inverter on the other hand. A classification and comparison of these strategies in terms of ripples reduction, tracking speed, switching loss, algorithm complexity and parameter sensitivity are presented. It is very difficult to conclude which is the best solution to improve the DTC performance. The choice of method depends on the application, cost, hardware availability, reliability and accuracy of the system. This review is expected to provide a very beneficial tool to all the industries and researchers working on electrical machine controls.

\section{Nomenclatures}

$\mathrm{v}_{\mathrm{s}(\alpha, \beta, \beta)} v_{r(\alpha, \beta)}: \alpha \beta$ components of the stator and rotor voltages

$i_{s(\alpha, \beta)}, i_{r(\alpha, \beta)}: \alpha \beta$ components of the stator and rotor currents

$\psi_{s(\alpha, \beta)}, \psi_{r(\alpha, \beta)}: \alpha \beta$ components of the stator and rotor flux $S_{1}, S_{2}, S_{3}$ : Switching states

$\mathrm{R}_{s}, \mathrm{R}_{\mathrm{r}}$ Stator and rotor resistances

$\mathrm{L}_{\mathrm{s}}, \mathrm{L}_{\mathrm{r}}$ : Stator and rotor Inductances

M: Mutual inductance

$\tau_{\mathrm{s}}, \tau_{\mathrm{r}}$ : Stator and rotor time constant

P: Pole pair number

$\sigma$ : Dispersion coefficient

$\omega_{\mathrm{s}}, \omega_{\mathrm{r}}:$ Stator and rotor pulsations

$\Omega$ : Mechanical pulsation

$\mathrm{T}_{\mathrm{r}}$ : Load torque

$\mathrm{T}_{\mathrm{em}}$ : Electromagnetic torque

$\Omega$ : Rotation speed of the machine

$\mathrm{J}$ : Moment of inertia

f: Coefficient of viscous friction

$\mathrm{U}_{\mathrm{c}}$ : $\mathrm{DC}$ bus voltage

$\theta_{\mathrm{s}}$ : Position of stator flux

$\mathrm{H}_{\text {Tem }}$ : Hysteresis band of torque electromagnetic

$\mathrm{H}_{\psi s}:$ Hysteresis band of stator flux

$\mathrm{K}_{\mathrm{i}}, \mathrm{K}_{\mathrm{p}}$ : Integral and proportional gains

$\varepsilon_{\mathrm{Ai}}$ : Error of the magnitude $\mathrm{Ai}$ 


\section{Abbreviations}

ANN: Artificial neural networks; DSVM: Discrete space vector modulation; DTC: Direct torque control; DTNC : Direct torque neural control; FLC: Fuzzy logic controller; FOC: Field oriented control; GA: Genetic algorithm; IM: Induction machine; MPC: Model predictive control; PI: Proportional integral; PWM: Pulse width modulation; SMC: Sliding mode control: SVM: Space vector modulation; THD: Total harmonics distortion; VSC: Variable structure contro

\section{Acknowledgements}

The authors would like to thank the anonymous reviewers for their helpful and constructive comments that greatly contributed to improving the final version of the paper. They would also like to thank the Editors for their generous comments and support during the review process.

\section{Funding}

The work is not supported by any funding agency. This is the authors own research work

\section{Availability of data and materials}

Data sharing not applicable to this article as no datasets were generated or analyzed during the current study.

\section{Authors' contributions}

$\mathrm{NE}, \mathrm{SM}$ and $\mathrm{AD}$ performed the study of improvement techniques of Direct Torque Control, $\mathrm{AE}$ and $\mathrm{AC}$ corresponding, engaged in modifying the paper and submitted it to the PCMP. SM, MT and YM checked the grammar and writing of the paper. All authors read and approved the final manuscript.

\section{Competing interests}

The authors declare that they have no competing interests.

\section{Author details}

${ }^{1}$ Laboratory of Production Engineering, Energy and Sustainable Development, Higher School of Technology, Sidi Mohamed Ben Abdellah University, Fez, Morocco. ${ }^{2}$ Faculty of Sciences and Technology, University of Bordj Bou Arreridj, Bordj Bou Arreridj, Algeria. ${ }^{3}$ Laboratory of Systems Integration and Advanced Technologies, Faculty of Sciences Dhar El Mahraz, Sidi Mohamed Ben Abdellah University, Fez, Morocco.

\section{Received: 22 October 2018 Accepted: 7 May 2019}

\section{Published online: 27 May 2019}

\section{References}

1. Hajian, M., Arab Markadeh, G. R., Soltani, J., \& Hoseinnia, S. (2009). Energy optimized sliding-mode control of sensorless induction motor drives. Energy Conversion and Management, 50, 2296-2306.

2. Saravanan, C., Sathiswar, J., \& Raja, S. (2012). Performance of three phase induction motor using modified stator winding. International Journal of Computer Applications, 46, 1-4.

3. Costa, B. L. G., Graciola, C. L., Angélico, B. A., Goedtel, A., \& Castoldi, M. F. (2018). Metaheuristics optimization applied to PI controllers tuning of a DTC-SVM drive for three-phase induction motors. Applied Soft Computing, $62,776-788$

4. Traoré, D., Leon, D., \& Glumineau, A. (2012). Adaptive interconnect observerbased backstepping control design for sensorless induction motor Automatica, 48, 682-687.

5. Karagiannis, D., Astolfi, A., Ortega, R., \& Hilairet, M. (2009). A nonlinear tracking controller for voltage-fed induction motors with uncertain load torque. IEEE Transactions on Control Systems Technology, 17, 608-619.

6. Sen, P. C. (1990). Electric motor drives and control-past, present, and future. IEEE Transactions on Industrial Electronics, 37, 562-575.

7. Trabelsi, R., Khedher, A., Mimouni, M. F., \& M'sahli, F. (2012). Backstepping control for an induction motor using an adaptive sliding rotor-flux observer Electric Power Systems Research, 93, 1-15.

8. Zaafouri, A., Regaya, C. B., Azza, H. B., \& Châari, A. (2016). DSP-based adaptive backstepping using the tracking errors for high-performance sensorless speed control of induction motor drive. ISA Transactions, 60, 333-347.

9. Alsofyani, I. M., \& Idris, N. R. N. (2013). A review on sensorless techniques for sustainable reliablity and efficient variable frequency drives of induction motors. Renewable and Sustainable Energy Reviews, 24, 111-121.
10. Derouich, A., \& Lagrioui, A. (2014). Real-time simulation and analysis of the induction machine performances operating at flux constant. International Journal Advanced Computer Science and Applications, 5, 59-64.

11. Jannati, M., Anbaran, S. A. Asgari, S. H., Goh, W. Y., Monadi, A. Junaidi, M. A. A., \& Idris, N. R. N. (2017). A review on variable speed control techniques for efficient control of single-phase induction motors: Evolution, classification, comparison. Renewable and Sustainable Energy Reviews, 75, 1306-1319.

12. Dos Santos, T. H., Goedtel, A., Da Silva, S. A. O., \& Suetake, M. (2014). Scalar control of an induction motor using a neural sensorless technique. Electric Power Systems Research, 108, 322-330.

13. Leonhard, W. (1994). Control of machines with the help of microelectronics. In Third IFAC symposium on control in power electronics and electrical drives (pp. 35-58).

14. Pereram, C., Blaabjerg, F., \& Pedersen, J. (2003). A Sensorless, stable V/F control method for permanent magnet synchronous motor drives. IEEE Transactions on Industry Applications, 39, 783-791.

15. Habbi, H. M. D., Ajeel, H. J., \& Inaam, I. A. (2016). Speed Control of induction motor using PI and V/F scalar vector controllers. International Journal of Computer Applications, 151, 36-43.

16. Martins, C. A., \& Carvalho, A. S. (2001). Technological trends in induction motor electrical drives. In IEEE Porto power tech proceedings (Vol. 2).

17. Amezquita-Brooks, L., Liceaga-Castro, E., Liceaga-Castro, J., \& Ugalde-Loo, C. E. (2015). Flux-torque cross-coupling analysis of FOC schemes: Novel perturbation rejection characteristics. ISA Transactions, 52, 446-461.

18. El Ouanjli, N., Derouich, A., El Ghzizal, A., Chebabhi, A., \& Taoussi, M. (2017). A comparative study between FOC and DTC controls of the doubly fed induction motor (DFIM). In International conference on electrical and information technologies: IEEE.

19. Mehazzem, F., Nemmour, A. L., \& Reama, A. (2017). Real time implementation of backstepping-multiscalar control to induction motor fed by voltage source inverter. International Journal of Hydrogen Energy, 42, 17965-17975.

20. Chikhi, A., Djarallah, M., \& Chikh, K. (2010). A comparative study of fieldoriented control and direct-torque control of induction motors using an adaptive flux observer. Serbian Journal of Electrical Engineering, 7, 41-55.

21. Profumo, F., DeDoncker, R., Ferraris, P.. \& Pastorelli, M. (1995). Comparison of universal field oriented (UFO) controllers in different reference frames. IEEE Transactions on Power Electronics, 10, 205-213.

22. Robyns, B., Berthereau, F., Hautier, J.-P., \& Buyse, H. (2000). A fuzzy-logicbased multimodel field orientation in an indirect $\mathrm{FOC}$ of an induction motor. IEEE Transactions on Industrial Electronics, 47, 380-388.

23. Novotny, D. W., \& Lipo, T. A. (1996). Vector control and dynamics of AC drives. Oxford: Clarendon

24. Takahashi, I., \& Noguchi, T. (1986). A new quick-response and high efficiency control strategy of an induction motor. IEEE Transactions on Industry Applications, IA-22(5), 820-827.

25. Depenbrock, M. (1988). Direct self control (DSC) of inverter-fed induction machine. IEEE Transactions on Power Electronics, 3, 420-429.

26. Vaez-Zadeh, S., \& Jalali, E. (2007). Combined vector control and direct torque control method for high performance induction motor drives. Energy Conversion and Management, 48, 3095-3101.

27. El Ouanjli, N., Derouich, A., El Gzizal, A., El Mourabet, Y., Bossoufi, B., \& Taoussi, M. (2017). Contribution to the performance improvement of doubly fed induction machine functioning in motor mode by the DTC control. International Journal Power Electronics and Drive System, 8, 1117-1127.

28. Khedher, A., \& Mimouni, M. F. (2010). Sensorless-adaptive DTC of double star induction motor. Energy Conversion and Management, 51, 2878-2892.

29. Reza, C. M. F. S., Islam, M. D., \& Mekhilef, S. (2014). A review of reliable and energy efficient direct torque controlled induction motor drives. Renewable and Sustainable Energy Reviews, 37, 919-932.

30. Kadir, A., Mekhilef, S., \& Ping, H. W. (2007). Direct torque control permanent magnet synchronous motor drive with asymmetrical multi level inverter supply. In Seventh international conference on power electronics (ICPE): IEEE (pp. 1196-1201).

31. Naik, V. N., Panda, A., \& Singh, S. P. (2016). A three-level fuzzy-2 DTC of induction motor drive using SVPW. IEEE Transactions on Industrial Electronics, 63, 1467-1479.

32. Abosh, A. H, Zhu, Z Q \& Ren, Y. (2017). Reduction of torque and flux ripples in space-vector modulation based direct torque control of asymmetric permanent magnet synchronous machine. IEEE Transactions on Power Electronics, 32, 2976-2986. 
33. Goel, N., Patel, R. N., \& Chacko, S. (2016). Torque ripple reduction of DTC IM drive using artificial intelligence. In International conference on electrical power and energy systems.

34. Sutikno, T., Idris, N. R. N., \& Jidin, A. (2014). A review of direct torque control of induction motors for sustainable reliability and energy efficient drives. Renewable and Sustainable Energy Reviews, 23, 548-558.

35. Panchade, V. M., Chile, R. H., \& Patre, B. M. (2013). A survey on sliding mode control strategies for induction motors. Annual Reviews in Control, 37, 289-307.

36. Buja, G., Casadei, D., \& Serra, G. (1997). Direct torque control of induction motor drives. In Proceedings of the IEEE international symposium on industrial electronics.

37. Slemon, G. R. (1989). Modelling of induction machines for electric drives. IEEE Transactions on Industry Applications, 25, 1126-1131.

38. Hafeez, M., Uddin, M. N., Rahim, N. A., \& Hew, W. P. (2014). Self-tuned NFC and adaptive torque hysteresis based DTC scheme for IM drive. IEEE Transactions on Industry Applications, 50, 1410-1420.

39. Kazemia, M. V., Moradib, M., \& Kazemic, R. V. (2012). Minimization of powers ripple of direct power controlled DFIG by fuzzy controller and improved discrete space vector modulation. Electric Power Systems Research, 89, 23-30

40. Yen-Shin, L., \& Jian-Ho, C. (2001). A new approach to direct torque control of induction motor drives for constant inverter switching frequency and torque ripple reduction. IEEE Transactions on Energy Conversion, 6, 220-227.

41. Pucci, M. (2012). Direct field oriented control of linear induction motors. Electric Power Systems Research, 89, 11-22.

42. Bonnet, F., Paul-Etienne, V., \& Pietrzak-David, M. (2007). Dual direct torque contro of doubly fed induction machine. IEEE Transactions on Industrial Electronics, 54 2482-2490.

43. El Mourabit, Y., Derouich, A., El Ghzizal, A., El Ouanjli, N., \& Zamzoum, O. (2017). DTC-SVM Control for permanent magnet synchronous generator based variable speed wind turbine. International Journal of Power Electronics and Drive System, 8, 1732-1743.

44. Talaeizadeh, V., Kianinezhad, R., Seyfossadat, S. G., \& Shayanfar, H. A. (2010). Direct torque control of six-phase induction motors using three-phase matrix converter. Energy Conversion and Management, 51, 2482-2491.

45. Beerten, J., Verveckken, J., \& Driesen, J. (2010). Predictive direct torque control for flux and torque ripple reduction. IEEE Transactions on Industrial Electronics, 57, 404-412.

46. Lokriti, A., Salhi, I., \& Doubabi, S. (2015). IM direct torque control with no flux distortion and no static torque error. ISA Transactions, 59, 256-267.

47. Singh, A. K., Reddy, C. U., Prabhakar, K. K., \& Praveen, K. (2015). FPGA implementation of direct torque control of induction motor with reduced ripples in torque and flux. In IEEE international transportation electrification conference.

48. Jonnala, R. B., \& Babu, C. S. (2018). A modified multiband hysteresis controlled DTC of induction machine with 27-level asymmetrical CHB-MLI with NVC modulation. Ain Shams Engineering Journal, 9, 15-29.

49. Sutikno, T., Nikldris, N. R., Jidin, A., \& Cirstea, M. N. (2013). An improved FPGA implementation of direct torque control for induction machines. IEEE Transactions on Industrial Informatics, 9(3), 1280-1290.

50. Giuseppe, S. B., \& Kazmierkowski, M. P. (2004). Direct torque control of PWM inverter-fed AC motors-A survey. IEEE Transactions on Industrial Electronics, 51, 744-757.

51. Ammarn, A., Bourek, A., \& Benakcha, A. (2017). Nonlinear SVM-DTC for induction motor drive using input-output feedback linearization and high order sliding mode control. ISA Transactions, 67, 428-442.

52. Casadei, D., Profumo, F., Serra, G., \& Tani, A. (2002). FOC and DTC: Two viable schemes for induction motors torque control. IEEE Transactions on Power Electronics, 17, 779-787.

53. Ammar, A., Benakcha, A., \& Bourek, A. (2017). Closed loop torque SVM-DTC based on robust super twisting speed controller for induction motor drive with efficiency optimization. International Journal of Hydrogen Energy, 42, 17940-17952.

54. Gadoue, S. M., Giaouris, D., \& Finch, J. W. (2009). Artificial intelligence-based speed control of DTC induction motor drives-A comparative study. Electric Power Systems Research, 79, 210-219.

55. Gdaim, S., Mtibaa, A., \& Mimouni, M. F. (2010). Direct torque control of induction machine based on intelligent techniques. International Journal of Computer Applications, 10, 0975-8887.

56. Belkacem, S., Naceri, F., \& Abdessemed, R. (2011). Improvement in DTC-SVM of $\mathrm{AC}$ drives using a new robust adaptive control algorithm. International Journal of Control, Automation, and Systems, 9, 267-275.
57. Rodriguez, J., Pontt, J., Silva, C., Kouro, S., \& Miranda, H. (2004). A novel direct torque control scheme for induction machines with space vector modulation. In IEEE annual power electronics specialists conference (pp. 13921397).

58. Abdelli, R., Rekioua, D., \& Rekioua, T. (2011). Performances improvements and torque ripple minimization for VSI fed induction machine with direct control torque. ISA Transactions, 50, 213-219.

59. El-Saadawi, M., \& Hatata, A. (2017). A novel protection scheme for synchronous generator stator windings based on SVM. Protection and Control of Modern Power Systems, 2(1), 24.

60. Pizzo, A. D., Marino, P., \& Visciano, N. (2002). Harmonic and interharmonic impact of DTC-based induction motor drives on 3-wire network. In IEEE international industrial electronics conference.

61. Maes, J., \& Melkebeek, J. (1998). Discrete time direct torque control of induction motors using back-EMF measurement. In Thirty-third IAS annual meeting industry applications conference.

62. Casadei, D., Serra, G., \& Tani, A. (2000). Implementation of a direct torque control algorithm for induction motors based on discrete space vector modulation. IEEE Transactions on Power Electronics, 15, 769-777.

63. Keyhani, H. R., Zolghadri, M. R., \& Homaifar, A. (2004). An extended and Improved discrete space vector modulation direct torque control for induction motors. In Annual IEEE power electronics specialists conference.

64. Del Toro, X. G., Arias, A., Jayne, M. G., Witting, P. A., Sala, V. M., \& Romeral, J. L. (2005). New DTC control scheme for induction motors fed with a threelevel inverter. Automatika, 46, 73-81.

65. Kyo-Beum, L., Joong-Ho, S., Choy, I., \& Ji-Yoon, Y. (2002). Torque ripple reduction in DTC of induction motor driven by three-level inverter with low switching frequency. IEEE Transactions on Power Electronics, 17, 255-264.

66. Utkin, I. V. (1993). Sliding mode control design principles and applications to electric drives. IEEE Transactions on Industrial Electronics, 40, 23-36.

67. Boubzizi, S., Abid, H., \& Chaabane, M. (2018). Comparative study of three types of controllers for DFIG in wind energy conversion system. Protection and Control of Modern Power Systems, 3(1), 21.

68. Tanvir, A., Beig, A. R., \& Al-Hosani, K. (2013). Sliding mode based DTC of three-level inverter fed induction motor using switching vector table. In Asian control conference.

69. Ayyarao, T. S. (2019). Modified vector controlled DFIG wind energy system based on barrier function adaptive sliding mode control. Protection and Control of Modern Power Systems, 4(1), 4

70. Rodic, M., \& Jezernik, K. (2002). Speed-sensorless sliding-mode torque control of an induction motor. IEEE Transactions on Industrial Electronics, 49, 87-95.

71. Mehmet, D. (2005). Sensorless sliding mode direct torque control (DTC) of induction motor. In Proceedings of the IEEE international symposium on industrial electronics.

72. Shir-Kuan, L., \& Chih-Hsing, F. (2001). Sliding-mode direct torque control of an induction motor. In Annual conference of the IEEE industrial electronics society (pp. 2171-2177).

73. Lascu, C., Boldea, I., \& Blaabjerg, F. (2004). Direct torque control of Sensorless induction motor drives: A sliding-mode approach. IEEE Transactions on Industry Applications, 40, 582-590

74. Detian, S. (2010). Sliding mode direct torque control for induction motor with robust stator flux observer. In International conference on intelligent computation technology and automation.

75. Camacho, E. F. (1993). Constrained generalized predictive control. IEEE Transactions on Automatic Control, 38(2), 327-332.

76. Camacho, E. F., \& Bordons, C. (2007). Model Predictive control. Advanced Textbooks in Control and Signal Processing, Springer-Verlag: London.

77. Geyer, T., Papafotiou, G., \& Morari, M. (2009). Model predictive direct torque control_Part I: Concept, algorithm, and analysis. IEEE Transactions on Industrial Electronics, 56, 1894-1905.

78. Zeinaly, Y., Geyer, T., \& Egardt, B. (2011). Trajectory extension methods for model predictive direct torque control. In 26th annual IEEE applied power electronics conference and exposition (APEC) (pp. 1667-1674).

79. Papafotiou, G., Kley, J., Papadopoulos, K. G., Bohren, P., \& Morari, M. (2009) Model predictive direct torque control-Part $\|$ : Implementation and experimental evaluation. IEEE Transactions on Industrial Electronics, 56, 19061915

80. Ezeonwumelu, I., Shinde, A. M., \& Gadiraju, V. M. (2007). Performance evaluation of DTC, MPDTC and DDTC methods for drive of a SPMSM. American Scientific Research Journal for Engineering, Technology, and Sciences (ASRJETS), 35(1), 201-214. 
81. Wang, F., Zhang, Z., Mei, X., Rodríguez, J., \& Kennel, R. (2018). Advanced control strategies of induction machine: Field oriented control, direct torque control and model predictive control. Energies, 11(1), 120.

82. Geyer, T., Papafotiou, G., \& Morari, M. (2009). Model predictive direct torque control-Part I: Concept, algorithm, and analysis. IEEE Transactions on Industrial Electronics, 56, 6.

83. Miranda, H., Cortés, P., \& Yuz, J. (2009). Predictive torque control of induction machines based on state-space models. IEEE Transactions on Industrial Electronics, 56, 6.

84. Pacas, M., \& Weber, J. (2005). Predictive direct torque control for the PM synchronous machine. IEEE Transactions on Industrial Electronics, 52, 5.

85. Okumus, H. I., \& Mustafa Aktas, M. (2010). Adaptive hysteresis band control for constant switching frequency in DTC induction machine drives. Turkish Journal of Electrical Engineering and Computer Sciences, 18, 59-69.

86. Uddin, M. N., \& Hafeez, M. (2012). FLC-based DTC scheme to improve the dynamic performance of an IM drive. IEEE Transactions on Industry Applications, 48, 823-831.

87. Jinlian, D., \& Tu, L. (2006). Improvement of direct torque control low-speed performance by using fuzzy logic technique. In IEEE international conference on mechatronics and automation.

88. Toufouti, R., Meziane, S., \& Benalla, H. (2007). Direct torque control for induction motor using intelligent techniques. Journal of Theoretical and Applied Information Technology, 3, 35-44.

89. Gdaim, S., Mtibaa, A., \& Mimouni, M. F. (2015). Design and experimental implementation of DTC of induction machine based on fuzzy logic control on FPGA. IEEE Transactions on Fuzzy Systems, 23, 644-655.

90. Zegai, M. L., Bendjebbar, M., Belhadri, K., Doumbia, M. L., Hamane, B., \& Koumba, P. M. (2015). Direct torque control of induction motor based on artificial neural networks speed Control using MRAS and neural PID controller. In IEEE electrical power and energy conference (EPEC).

91. Yuan, G., Jinkuan, W., \& Xinyun, Q. (2011). The improvement of DTC system performance on fuzzy control. Procedia Environmental Sciences, 10, 589-594.

92. Zhao, T., Fenghong, X., Jianping, W., Zhang, G., \& Jianlin, M. (2014). Research on speed sensorless direct torque fuzzy control of induction motors. In International conference on electronics and communication systems.

93. Klement, E. P., \& Slany, W. (1997). Fuzzy logic in artificial intelligence. In Book: Encyclopedia of computer science and technologychapter (p. 34) Suppl. 19.

94. Venugopal, C. (2010). Fuzzy logic based DTC for speed control of Matrix Converter fed Induction Motor. In 2010 IEEE International Conference on Power and Energy (pp. 753-758). IEEE.

95. El Ouanjli, N., Derouich, A., El Ghzizal, A., Chebabhi, A., Taoussi, M., \& Bossoufi, B. (2018). Direct torque control strategy based on fuzzy logic controller for a doubly fed induction motor. In IOP conference series: Earth and environmental science (Vol. 161, No. 1, p. 012004). IOP Publishing.

96. Tlemcani, A., Bouchhida, O., Benmansour, K., Boudana, D., \& Boucherit, M. S. (2009). Direct torque control strategy (DTC) based on fuzzy logic controller for a permanent magnet synchronous machine drive. Journal of Electrical Engineering \& Technology, 4, 66-78.

97. Mir, S. A., Zinger, D. S., \& Elbuluk, E. (1993). Fuzzy implementation of direct self control of induction machines. In IEEE conference on industry applications society annual meeting.

98. Jagadish, H. P., \& Kodad, S. F. (2009). Direct torque fuzzy control of an AC drive. In IEEE international conference on advances in computing, control, and telecommunication technologies

99. Hafeez, M., Uddin, M. N., \& Rebeiro, R. S. (2010). FLC based hysteresis band adaptation to optimize torque and stator flux ripples of a DTC based IM drive. In IEEE electric power and energy conference.

100. El Ouanjli, N., Taoussi, M., Derouich, A., Chebabhi, A., El Ghzizal, A., \& Bossoufi, B. (2018). High performance direct torque control of doubly fed using fuzzy logic. Gazi University Journal of Science, 31(2), 532-542.

101. Mondal, S. K., Pinto, J. O., \& Bimal, K. B. (2002). A neural-network-based space-vector PWM controller for a three-level voltage-fed inverter induction motor drive. IEEE Transactions on Industry Applications, 38, 660-669.

102. Faa-Jeng, L., Jyh-Chyang, Y., \& Mao-Sheng, T. (2001). Sensorless induction spindle motor drive using fuzzy neural network speed controller. Electric Power Systems Research, 58, 187-196.

103. Alessandro Goedtel, A., Da-Silva, I. N., \& Amaral, S. P. J. (2007). Load torque identification in induction motor using neural networks technique. Electric Power Systems Research, 77, 35-45.
104. Singh, B., Pradeep, J., Mittal, A. P., \& Gupta, J. R. P. (2006). Neural network based DTC IM drive for electric vehicle propulsion system. In IEEE conference on electric and hybrid vehicles.

105. Berrabah, F., Salah, S., \& Chebabhi, A. (2016). SVM technique based on DTC sensorless control optimized by ANN applied to a double stator asynchronous machine fed by three-level six-phase inverter. The Mediterranean Journal of Measurement and Control, 12, 571-579.

106. Hammoumi, A., Massoum, A., Meroufel, A., \& Wira, P. (2012). Application des Réseaux de Neurones pour la Commande de la Machine Asynchrone sans capteur mécanique. Acta Electrotehnica, 53, 99-104.

107. Zemmit, A., Messalti, S., \& Harrag, A. (2016). Innovative improved direct torque control of doubly fed induction machine (DFIM) using artificial neural network (ANN-DTC). International Journal of Applied Engineering, 11, 9099-9105.

108. Jadhav, S., Kirankumar, J., \& Chaudhari, B. (2012). ANN based intelligent control of induction motor drive with space vector modulated DTC. In IEEE international conference power electron, drives energy systems (PEDES) (pp. 1-6).

109. Grzesiak, L. M., \& Ufnalski, B. (2005). DTC drive with ANN-based stator flux estimator. In European conference on power electronics and applications.

110. Bossoufi, B., Karim, M., Silviu, S., \& Lagrioui, A. (2011). DTC Control based artificial neural network for high performance PMSM drive. Journal of Theoretical and Applied Information Technology, 33, 165-176.

111. Grzesiak, L. M., Meganck, V., Sobolewski, J., \& Bartlomiej, U. (2006). On-line trained neural speed controller with variable weight update period for direct-torque-controlled AC drive. In 12th international power electronics and motion control conference (pp. 1127-1132).

112. Kumar, R., Gupta, R., Bhangale, S., \& Gothwal, H. (2007). Artificial neural network based direct torque control of induction motor drives. In IET-UK international conference on information and communication technology in electrical sciences (pp. 361-367).

113. Lin, F. J., Chou, W. D., \& Huang, P. K. (2003). Adaptive sliding-mode controller based on real-time genetic algorithm for induction motor servo drive. In IEE proceedings - electric power applications (pp. 1-13).

114. Mma, M. A., \& Walcott, B. L. (1996). Stability and optimality in genetic algorithm controllers. In IEEE international symposium on intelligent control.

115. Naresh, B., Kumar, M. V., \& Yadaiah, N. (2011). GA based tuning of PI controller. In IEEE recent advances in intelligent computational systems.

116. Zemmit, A., Messalti, S., \& Harrag, A. (2017). A new improved DTC of doubly fed induction machine using GA-based PI controller. Ain Shams Engineering Journal, 9(4), 1877-1885.

117. Gadoue, S. M., Giaouris, D., \& Finch, J. W. (2007). Genetic algorithm optimized PI and fuzzy sliding mode speed Control for DTC drives. In Proceedings of the world congress on engineering.

118. Hao, L., Qiuyun, M., \& Zhilin, Z. (2010). Research on direct torque control of induction motor based on genetic algorithm and fuzzy adaptive PI controller. In International conference on measuring technology and mechatronics automation

119. Tripathi, S. M., Tiwari, A. N., \& Singh, D. (2015). Grid-integrated permanent magnet synchronous generator based wind energy conversion systems: A technology review. Renewable and Sustainable Energy Reviews, 51, 1288-1305.

120. Kumar, R. H., lqbal, A., \& Lenin, N. C. (2017). Review of recent advancements of direct torque control in induction motor drives-a decade of progress. IET Power Electronics, 11(1), 1-15.

121. Niu, F., Wang, B., Babel, A. S., Li, K., \& Strangas, E. G. (2016). Comparative evaluation of direct torque control strategies for permanent magnet synchronous machines. IEEE Transactions on Power Electronics, 31(2), 1408-1424 